www.jmscr.igmpublication.org

Impact Factor 5.84

Index Copernicus Value: 83.27

ISSN (e)-2347-176x ISSN (p) 2455-0450

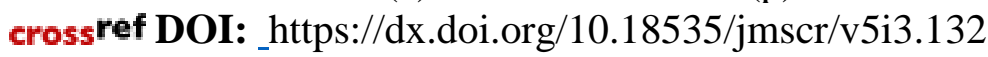

Journal Of Medical Science And Clinical Research

\title{
A Clinical Trial to Study the Effect of 5 Week Core Strengthening Protocol on Shoulder Strength in Young Obese Individuals
}

\author{
Authors

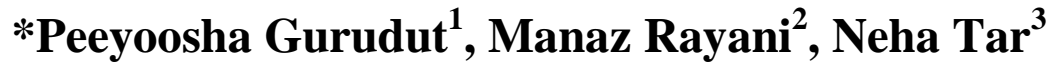 \\ Department of Orthopaedics Physiotherapy \\ KLE University's Institute of Physiotherapy, Belagavi \\ Corresponding Author \\ Peeyoosha Gurudut \\ Associate Professor, Orthopaedic Physiotherapy \\ KLE University's Institute of Physiotherapy, Belagavi-590010, Karnataka, India \\ Email: peeoo123@yahoo.com Contact info- +919844821355, Tel: 0831-2473906 Fax 0831-2474727
}

\begin{abstract}
It is already known that the core plays an important role in the kinetic chain, since it is the centre of all functional movements. Previous researches have proved that isometric shoulder exercises elicit greatest level of activation of trunk musculature. But there are no studies stating that, core strengthening can have an effect on shoulder strength in young obese individuals. Hence, the purpose of this study was to evaluate the effect of 5 week core strengthening protocol on shoulder strength and core in young obese individuals. Twenty four young obese individuals having BMI $\geq 30 \mathrm{~kg} / \mathrm{m}^{2}$ and waist circumference $\geq 94 \mathrm{~cm}$ for men and $\geq 80 \mathrm{~cm}$ for women participated in a 5 week core strengthening protocol. Outcome measures were a Hand held Dynamometer to evaluate the shoulder strength and a pressure biofeedback unit for core strength. The 5 week core strengthening protocol had a significant improvement in dominant and non-dominant shoulder strength for all six shoulder movements $(p<0.001)$ and core strength $(p<0.001)$. It was concluded that five week core strengthening protocol has a significant impact on bilateral shoulder strength in young obese individuals.

Keywords: Overweight, obesity, core, kinetic chain, muscle strength, core strengthening.
\end{abstract}

\section{INTRODUCTION}

Overweight and obesity are defined as abnormal or excessive fat accumulation that presents a risk to health. Worldwide there are over 1.5 billion adults with a body mass index $(\mathrm{BMI})>25 \mathrm{~kg} / \mathrm{m}^{2}$, who are classified as overweight. ${ }^{(1)}$ Findings on prevalence of obesity in India which was conducted in the states of Tamil Nadu, Maharashtra and Jharkhand and one Union Territory was shown to be 135, 153 and 107 million individuals with general obesity, abdominal obesity and central obesity, respectively. ${ }^{(2)}$ Waist circumference and BMI are widely used for assessment of obesity. ${ }^{(3)}$ BMI a clinical indicator of total adiposity whereas waist circumference is an indicator of central adiposity. ${ }^{(4)} \mathrm{A}$ crude population measure of obesity is the body mass index (BMI), a person's weight (in kilograms) divided by the square of his height (in meters). ${ }^{(3)}$ A person with a BMI of $>/=30 \mathrm{~kg} / \mathrm{m}^{2}$ and waist 
circumference $>/=94 \mathrm{~cm}$ for men and $>/=80 \mathrm{~cm}$ for women is generally considered as obese. ${ }^{(1),(5)}$ The problem with the rising level of obesity is the associated risk of developing a variety of systemic problems. Adult obesity has been associated with a higher prevalence of musculoskeletal problems. Obesity is associated with physiological changes at the muscle level, including a decrease in capillary density and blood flow thereby limiting the supply of oxygen and energy sources. When performing sustained contractions these physiological changes reduce recovery efficiency and may thereby lead to a faster onset of muscle fatigue. ${ }^{(1)}$ This can further lead to loss of muscle function and performance.

Increase in the amount of adipose tissue has been proposed as a risk factor for sarcopenia and this relationship is receiving increased critical attention. Fatty infiltration of muscle is associated with reduced strength. Further, increasing central adiposity could also influence muscle function through increased levels of insulin resistance. ${ }^{(4)}$

Studies have proved that the obese individuals with central obesity have weak muscle strength as compared to lean individuals. ${ }^{(6)}$ A cohort study was conducted to find cross-sectional associations between different measures of obesity and muscle strength in men and women in a British population. The study concluded that high waist circumference was associated with lower grip strength and in contrast, higher BMI was associated with stronger grip strength. ${ }^{(4)}$ Obesity and aging can also modify job demands and affect worker capacity in terms of muscular function. In obese individuals, studies have assessed upper limb task at workplace in comparison with nonobese people, the study involved two experimental sessions which concluded that performance declines with higher BMI. ${ }^{(1)}$

In people with abdominal or central obesity which is measured by higher waist circumference, the core muscles are strengthened to reduce regional fat and improve core stability. ${ }^{(15)}$ The core muscle strengthening is an important aspect of training protocol in obese individuals with predominant abdominal obesity. The "core" is defined as a box with the abdominals in the front, Paraspinals and Gluteals in the back, the Diaphragm as the roof, and the Pelvic Floor and hip girdle musculature as the bottom. ${ }^{(7)}$

Core stability is important for efficient biomechanical function to maximise force generation and minimise joint loads in all types of activities ranging from running to throwing. ${ }^{(8)}$ Core has been linked through a kinetic chain formed with lower and upper extremities. Hence, the core is centre to all forms of functions and performance tasks. The stronger core will help to maximize upper and lower extremity function. ${ }^{(9)}$

Various studies have proved a positive correlation between core stability and lower extremity functions and injuries in normal ${ }^{(10)}$, athletic (11) and patient population. ${ }^{(7)}$ Studies have also shown the positive relation between core strength and upper extremity functional performance in golfers ${ }^{(12)}$, tennis players ${ }^{(3,13)}$ and cricket bowlers ${ }^{(9)}$ in parameters like drive distance, serve velocity and throwing respectively.

Furthermore, in a study on normal individuals, isometric shoulder strengthening exercises have shown to recruit core muscles which were shown through Electromyographic findings previously. ${ }^{(10)}$ There have been studies which have assessed the effect ofcore strengthening on abdominal obesity ${ }^{(14,15)}$ but there is lacuna in literature where studiesare done to assess the effect of core strengthening on shoulder strength in young obese population. Hence, the present study intended to assess the effect of core strengthening on shoulder strength in young obese population.

\section{MATERIALS AND METHODS Study Design and Setting}

This research study was a single group pre post study design with a sample of convenience. Ethical clearance for the study was obtained by the Institutional Ethical Review Committee following which the study participants were screened for inclusion and exclusion criteria. All participants gave written informed consent prior to 
commencement of the study. The rights of the participants were protected throughout the trial.

\section{Participants}

33 young obese individuals who volunteered were assessed for eligibility for inclusion and exclusion criteria and out of which 24 subjects were enrolled.[Refer CONSORT flowchart]The inclusion criteria were 1) Young obese individuals having BMI $\geq 25 \mathrm{~kg} / \mathrm{m}^{2}$ and waist circumference $\geq 94 \mathrm{~cm}$ in males and $\geq 80 \mathrm{~cm}$ in females.2) Individuals with level 1, 2 and 3 by Sahrmann testing protocol for core strength. Participants were excluded if they had 1) Any recent injuries to the upper extremities and spine in the last 12 months.2) History of surgery done on spine, upper limb and abdomen. 3) Individual under any type of physical training.4) Any known systemic illnesses and 5) Any Neurological disorders.

\section{Intervention}

The core training program consisted of 5 - week series of one hour core strengthening exercise for three days per week. Exercises were performed on a mat. Each exercise session began with warm up exercises(10mins) and ended with cool down exercises (5mins) (refer table: 1). The intensity of core training protocol was determined by using the Karvonen method to calculate the Target Heart Rate. The intensity of exercises was progressively increased with increase in the number of repetitions. The target heart rate during the first week was $40 \%$ of Maximal Heart Rate which was increased by $10 \%$ every week, reaching $80 \%$ MHR by $5^{\text {th }}$ week. ${ }^{(16)}$

Target Heart Rate $=\mathrm{HR}_{\text {rest }}+60-40-80 \%\left(\mathrm{HR}_{\max }\right.$ $-\mathrm{HR}_{\text {rest }}$ )

Max. Heart Rate $=220-$ Age

1. During the first week, the subjects performed 3 repetitions of each exercise.

2. During the second week, the subjects performed 4 repetitions of each exercise.

3. During the third week, the subjects performed 5 repetitions of each exercise.
4. During the fourth week, the subjects performed 6 repetitions of each exercise for one session followed by 7 repetitions of each exercise for second and third session.

5. During the fifth week, the subjects performed 8 repetitions of each exercise.

The protocol consisted of 23 exercises ${ }^{(16)}$ which followed the principles of core strengthening and all exercises were done under the supervision of certified physiotherapist.[Refer Table1\& Image 3]

\section{Outcome Assessment:}

Core Strength- Was measured using a Pressure Biofeedback (Chattanooga group, USA), as it is simple and feasible equipment and is known to have moderate to good reproducibility and acceptable construct. ${ }^{(17)}$ [Refer image 4] Here, the individual was made to lie in supine/ crook lying position. The pressure biofeedback was placed in the lumbar lordosis (centered about L3). The pad was inflated to a base pressure of $40 \mathrm{mmHg}$. Keeping the knees bent and the lumbar spine neutral (no pressure change), the individual was instructed to slowly lift both feet off the floor until both hips are flexed to $90^{\circ}$ and readings were measured in mmHg.[Refer Image 1]

Shoulder strength- Was measured using a Hand held dynamometer (Baseline hydraulic dynamometer, manufactured by white plains, NY, 10602 USA), as it an evaluation tool which is simple to assess and measure and is highly sensitive, reproducible and contributes to a valuable data. (18),(19) [Refer image 4]in which; the subject applied maximal force that was resisted by the examiner. A total of 6 shoulder movements were assessed i.e. flexion, extension, adduction, abduction, horizontal adduction and horizontal abduction [Refer Image 2] for dominant and nondominant side shoulders. The readings were noted in units of kilograms.

\section{Data Collection}

Demographic data for age, gender, height, weight, BMI, hand dominance, Sahrmann level and waist 
circumference were collected from all the participants. The core strengthening program consisted of 3 sessions per week for 5 consecutive weeks i.e. 15 sessions in total. The outcome measures were assessed twice i.e. before commencement of exercises and at the end of $5^{\text {th }}$ week.

\section{Statistical analysis}

A sample size of 24 participants was calculated using the formula $\mathrm{N}=2\left(\mathrm{Z}_{\alpha}+\mathrm{Z}_{\beta}\right)^{2} \times \mathrm{S}^{2} / \mathrm{d}^{2}$ where $Z$ value for $\alpha$ error is 1.96 , for $\beta$ with $80 \%$ power $=0.84 . S$ and $D$ being the average standard deviation and mean difference from reference article respectively. Statistical analysis was done using SPSS software of $20^{\text {th }}$ version. For different quantitative parameters, mean and SD were calculated. Data was computed and analysed using paired $\mathrm{t}$ test. Probability values less than 0.001 were considered statistically significant.

\section{RESULTS}

Age of the participants in the study was between 18 to 25 years with a mean age being $21.17 \pm$
1.43. The mean BMI of the participants was $32.49 \pm 2.50$ and mean waist circumference being105.08 \pm 10.06 . Sahrmann level of all the participants was 3 .Out of 24 subjects 21 were right dominant and 3 were left dominant. There was female predominance in the study group where $90 \%$ subjects were females and 10\% subjects were males. Incidentally it was found that non dominant side was stronger than the dominant side, but the results were not analysed

When shoulder strength scores were compared for pre and post intervention, statistically significant improvement was noted in all the 6 movements of shoulder that were assessed (p-value <0.001)after 5 weeks of core strengthening which indicates that there is a positive effect of core strengthening on overall shoulder strength. The findings were similar for both dominant and non-dominant sides. The results also showed significant improvement in core strength when pre post scores were compared. [Refer table 2,3\& 4]

Table 1: List of Core Strengthening Exercises Prescribed.

\begin{tabular}{|l|ll|}
\hline Warm up & Exercises & \\
\hline Breathing & The hundred & Pelvic curl \\
\hline Imprint and release & The shoulder bridge & Side bend \\
\hline Spinal rotation & Single leg circle & Side kick front \\
\hline Cat stretch & One leg stretch & Side kick back \\
\hline Hip rolls & Double leg stretch & The saw \\
\hline Scapula isolation & Rolling like a ball & Roll-up \\
\hline Arm circles & Leg pull down & Spine Stretch forward \\
\hline & Leg pull up & Push-up \\
\hline
\end{tabular}

Table 2 : Depicting Pre Post Differences of Dominant Side Shoulder Strength.

\begin{tabular}{|c|c|c|c|c|}
\hline Variables & Time & Mean \pm SD & Paired $\mathrm{t}$ & $\mathrm{P}$-value \\
\hline \multirow[t]{2}{*}{ Flexion } & Pretest & $12.71 \pm 3.71$ & \multirow[b]{2}{*}{-16.1269} & \multirow[b]{2}{*}{$0.0001 *$} \\
\hline & Posttest & $14.46 \pm 3.79$ & & \\
\hline \multirow[t]{2}{*}{ Extension } & Pretest & $12.83 \pm 2.97$ & \multirow[b]{2}{*}{-18.8693} & \multirow[b]{2}{*}{$0.0001 *$} \\
\hline & Posttest & $16.04 \pm 3.13$ & & \\
\hline \multirow[t]{2}{*}{ Abduction } & Pretest & $12.13 \pm 3.10$ & \multirow[b]{2}{*}{-3.6067} & \multirow[b]{2}{*}{$0.0015^{*}$} \\
\hline & Posttest & $13.33 \pm 2.60$ & & \\
\hline \multirow[t]{2}{*}{ Adduction } & Pretest & $12.88 \pm 3.15$ & \multirow[b]{2}{*}{-5.4294} & \multirow[b]{2}{*}{$0.0001 *$} \\
\hline & Posttest & $15.25 \pm 3.59$ & & \\
\hline \multirow[t]{2}{*}{ Horizontal Abduction } & Pretest & $12.08 \pm 2.69$ & \multirow[b]{2}{*}{-10.4753} & \multirow[b]{2}{*}{$0.0001 *$} \\
\hline & Post test & $14.17 \pm 2.79$ & & \\
\hline \multirow[t]{2}{*}{ Horizontal Adduction } & Pretest & $11.83 \pm 2.90$ & \multirow[b]{2}{*}{-12.1075} & \multirow[b]{2}{*}{$0.0001 *$} \\
\hline & Posttest & $13.75 \pm 3.01$ & & \\
\hline
\end{tabular}

*statistically significant $\mathrm{p}<0.001$ 
Table 3: Depicting Pre Post Differences of Non-Dominant Side Shoulder Strength.

\begin{tabular}{|c|c|c|c|c|}
\hline Variables & Time & Mean \pm SD & t-value & $\mathrm{p}$-value \\
\hline \multirow[t]{2}{*}{ Flexion } & Pretest & $12.29 \pm 3.01$ & \multirow[b]{2}{*}{-12.58} & \multirow[b]{2}{*}{$0.0001 *$} \\
\hline & Posttest & $14.29 \pm 2.99$ & & \\
\hline \multirow[t]{2}{*}{ Extension } & Pretest & $13.17 \pm 3.36$ & \multirow[b]{2}{*}{-13.3397} & \multirow[b]{2}{*}{$0.0001 *$} \\
\hline & Posttest & $16.67 \pm 3.70$ & & \\
\hline \multirow[t]{2}{*}{ Abduction } & Pretest & $12.13 \pm 3.23$ & \multirow[b]{2}{*}{-8.5374} & \multirow[b]{2}{*}{$0.0001 *$} \\
\hline & Posttest & $14.00 \pm 3.22$ & & \\
\hline \multirow[t]{2}{*}{ Adduction } & Pretest & $13.67 \pm 3.41$ & \multirow[b]{2}{*}{-14.2290} & \multirow[b]{2}{*}{$0.0001 *$} \\
\hline & Posttest & $15.75 \pm 3.63$ & & \\
\hline \multirow[t]{2}{*}{ Horizontal Abduction } & Pretest & $11.21 \pm 1.96$ & \multirow[b]{2}{*}{-11.9832} & \multirow[b]{2}{*}{$0.0001 *$} \\
\hline & Post test & $14.00 \pm 2.11$ & & \\
\hline \multirow{2}{*}{$\begin{array}{l}\text { Horizontal } \\
\text { Adduction }\end{array}$} & Pretest & $11.50 \pm 2.27$ & \multirow[b]{2}{*}{-8.5639} & \multirow[b]{2}{*}{$0.0001 *$} \\
\hline & Posttest & $13.67 \pm 2.48$ & & \\
\hline
\end{tabular}

*statistically significant $\mathrm{p}<0.001$

Table 4: Depicting Pre Post Differences of Core Strength.

\begin{tabular}{|l|c|c|c|c|c|}
\hline Time & Mean \pm SD & Mean Diff. \pm SD & \% of change & Paired t & P-value \\
\cline { 1 - 2 } Pretest & $65.25 \pm 21.70$ & \multirow{2}{*}{$-25.69 \pm 5.82$} & -39.37 & -21.6108 & $0.0001^{*}$ \\
\hline Posttest & $90.94 \pm 19.85$ & $p<0.001$
\end{tabular}

\section{Consort Flowchart}

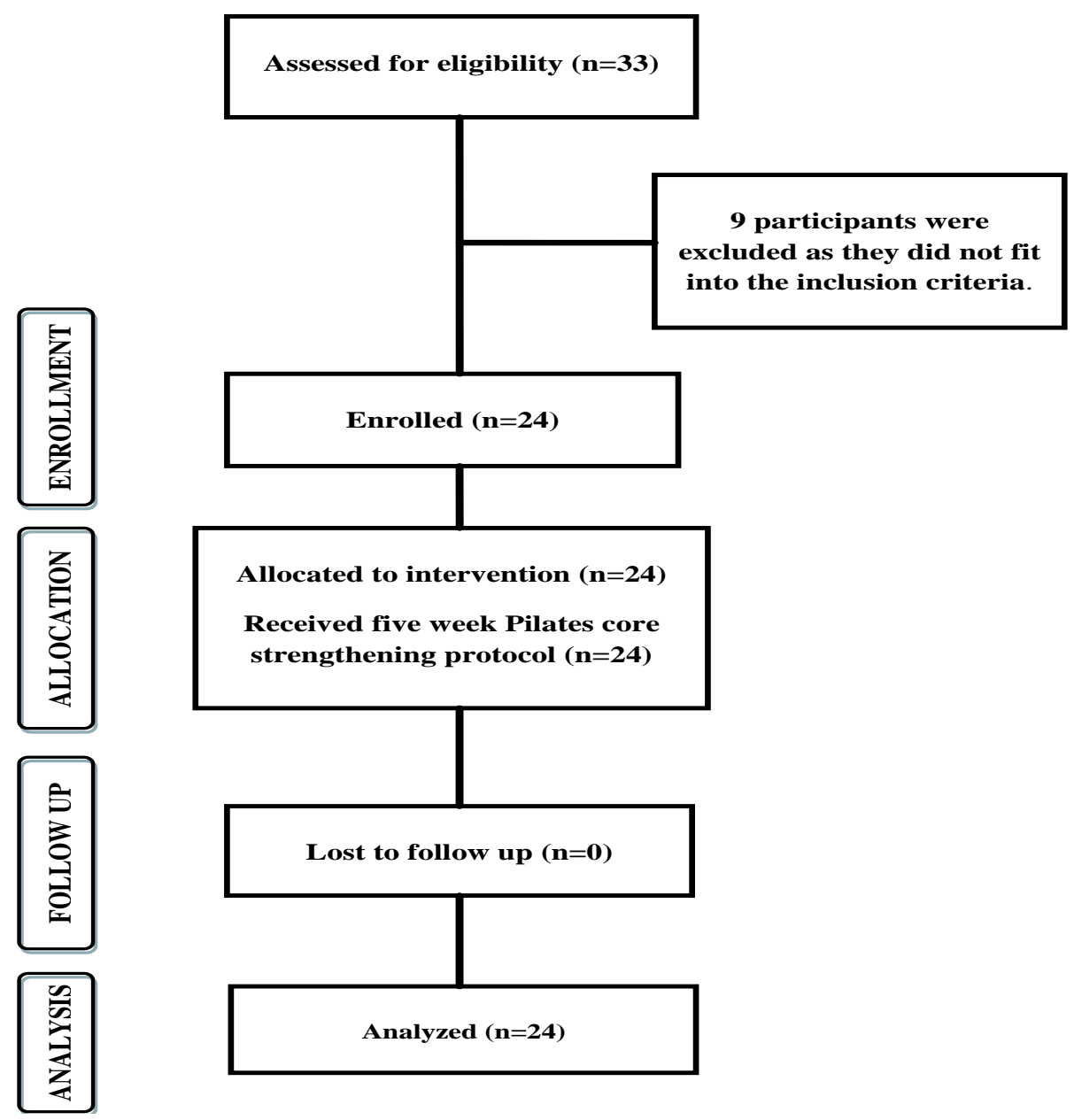




\begin{tabular}{|l|l|}
\hline JMSCR Vol||05||Issue||03||Page 19144-19153\|March & 2017 \\
\hline
\end{tabular}

Image 1: Depicting Core Strength Assessment Using a Pressure Biofeedback Unit.
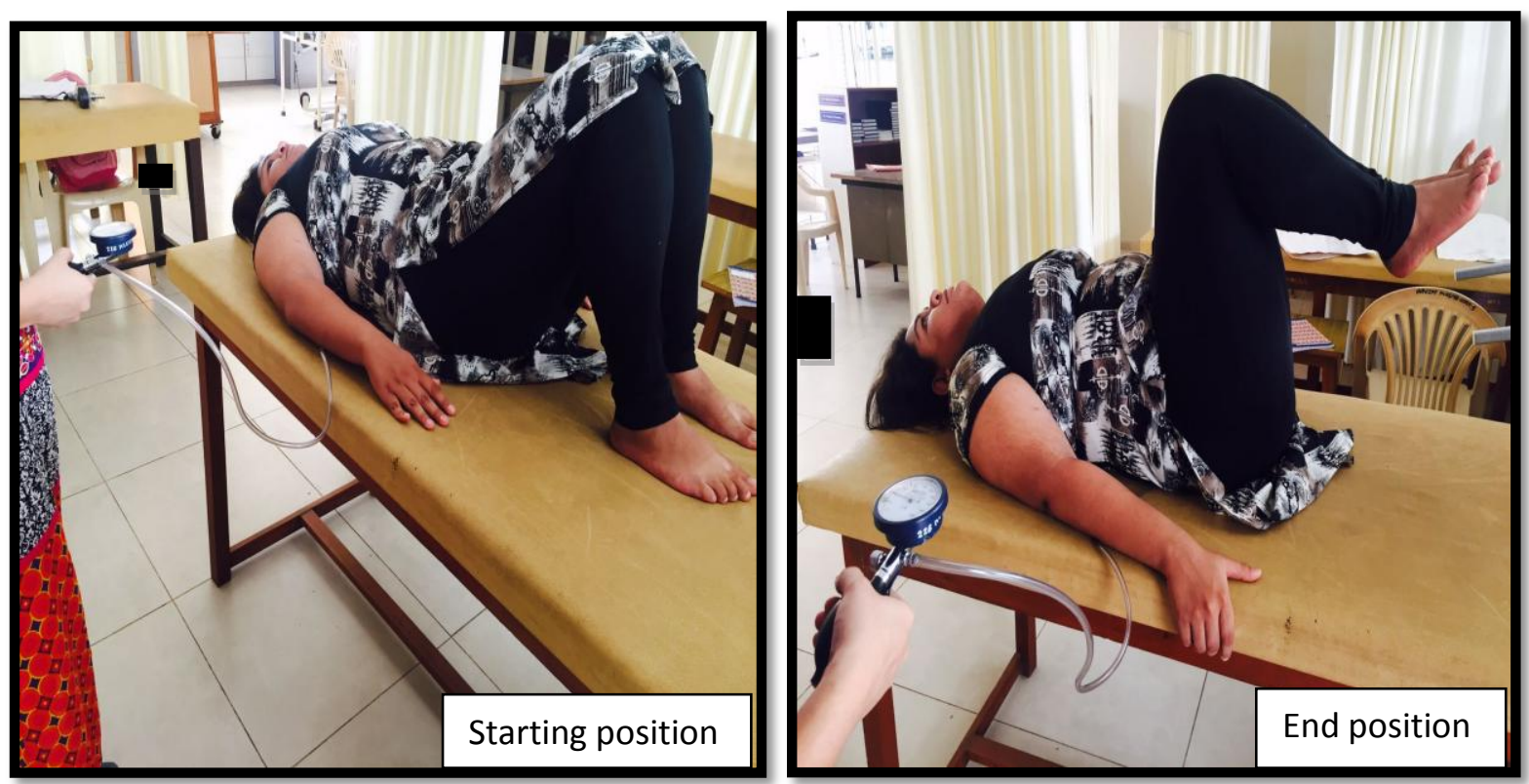

Image 2: Depicting the Assessment of Shoulder Strength Using a Hand Held Dynamometer.
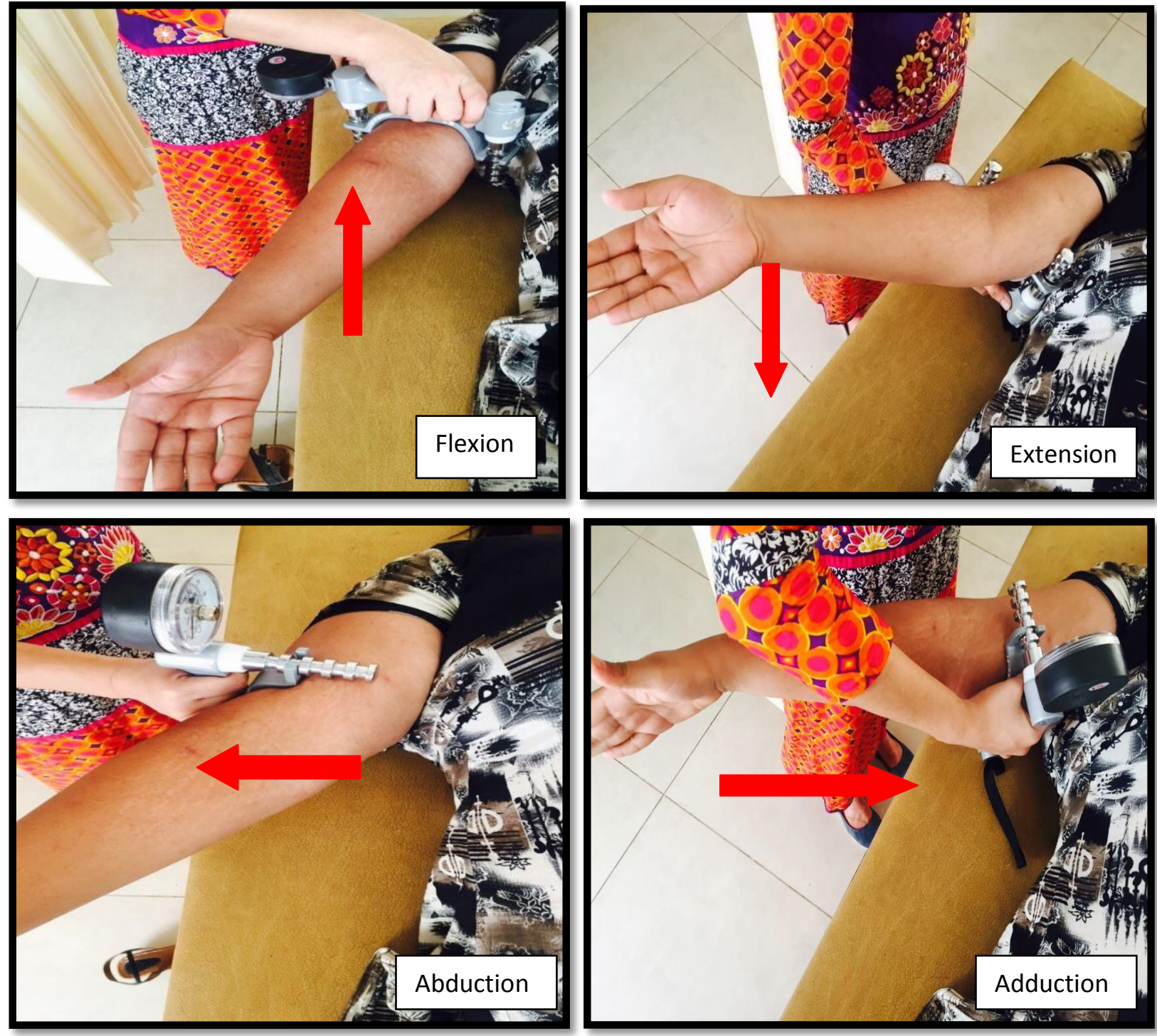

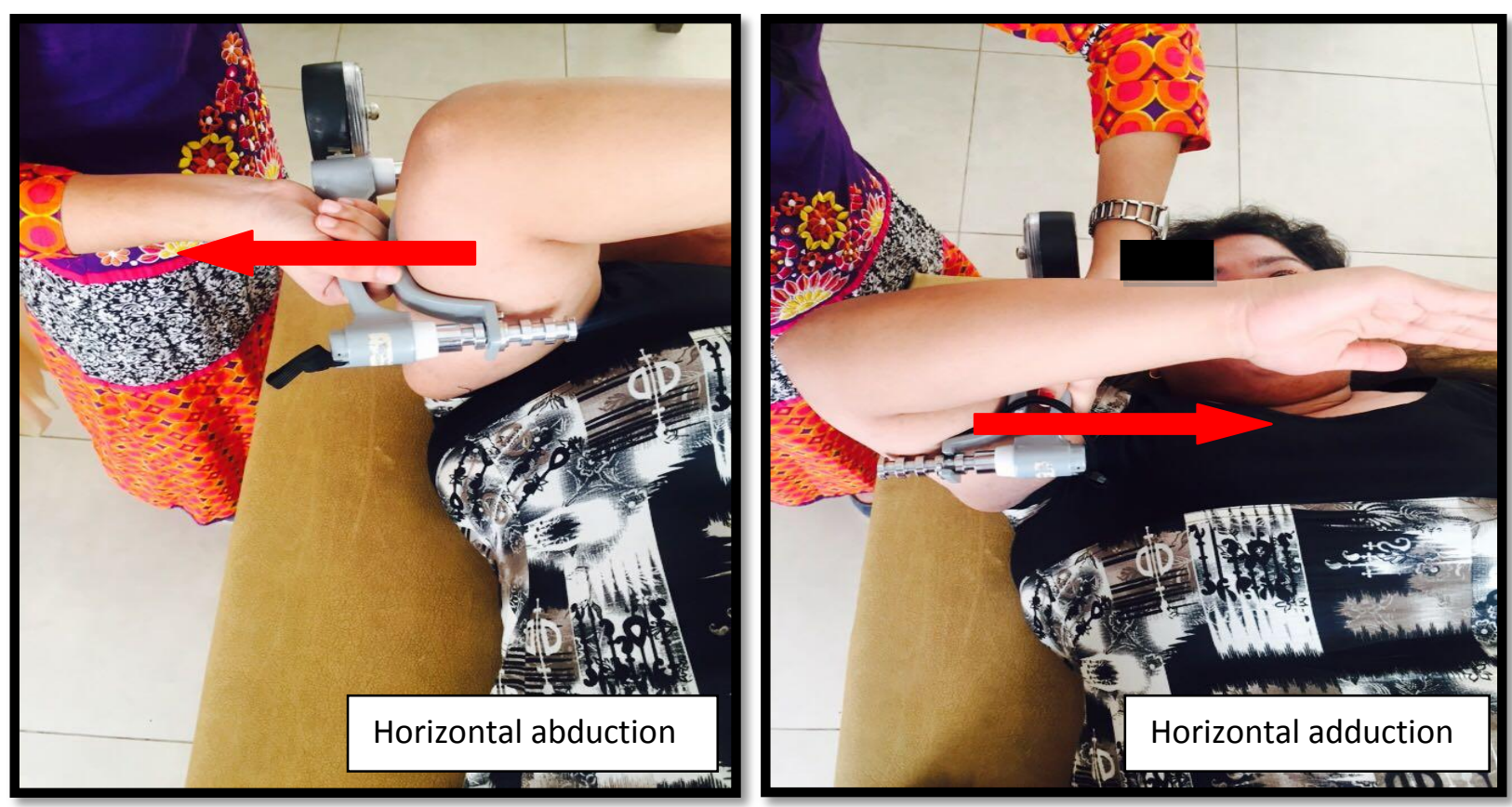

Image 3: Depicting Core Strengthening Exercise Protocol

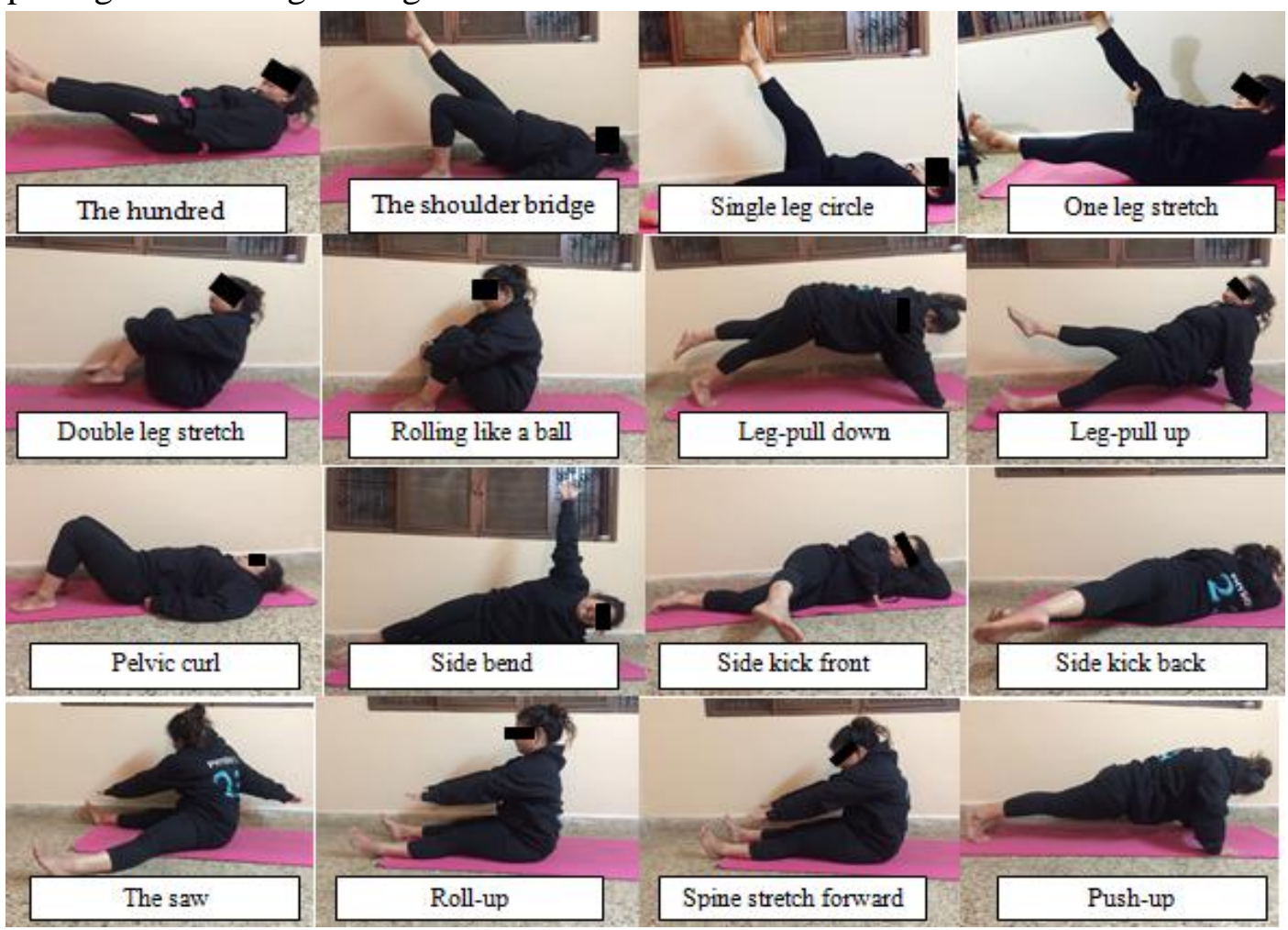

Image 4: Depicting Tools Used For Assessment Of Core And Shoulder Strength.

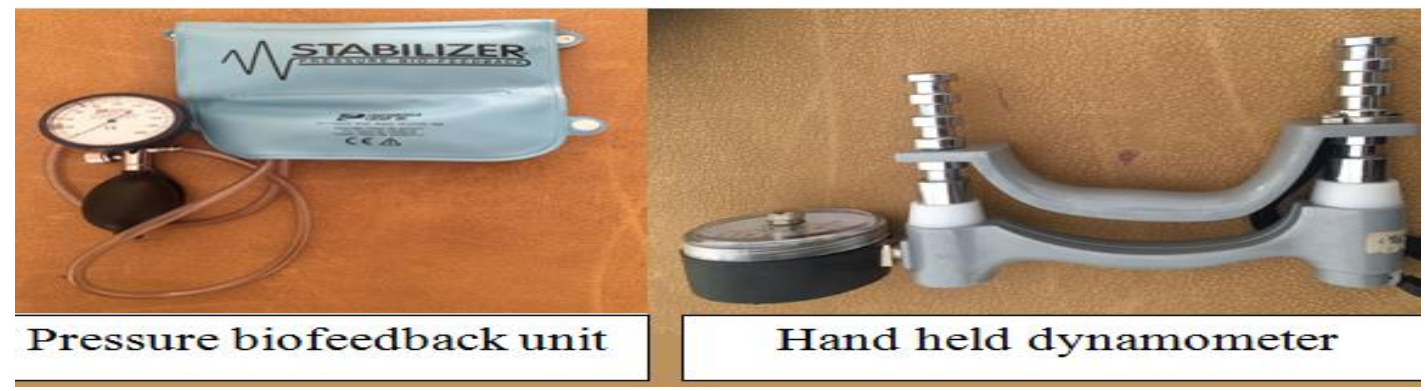




\section{DISCUSSION}

The present clinical trial was done with an objective to evaluate the effect of five week core strengthening protocol on core and shoulder strength of both the dominant and non- dominant sides in young obese individuals. The results from statistical analysis of the present study support the alternate hypothesis that core strengthening has a significant effect on the improvement of shoulder strength of both dominant and non-dominant sides following the five week core strengthening protocol.

In the present study, young obese individuals between the age group of 18 to 25 years were included. World Health Organization had conducted a study to evaluate the prevalence of obesity which concludes that obesity has become a major health challenge in the young individuals and it also states that the prevalence of obesity is more in women as compared to men. ${ }^{(20)}$ The present study accords with the above study as it includes more obese females than obese males.

Obesity impairs functional performance reflected by higher rates of strength loss. Obese individuals also have shorter endurance as compared to nonobese. ${ }^{1}$ They are also known to have a higher fatigue level, as in obese individuals added body mass with obesity includes some additional muscle mass. ${ }^{(21)}$ Hence, in the present study core strengthening exercises were given to help in increasing the muscle strength, endurance and flexibility ${ }^{(22),(23),(24)}$ which in turn may help obese function effectively.

The present study demonstrated significant improvement of core strength after 5 week training. The improvement in the strength can be attributed to various physiological changes like activation of core muscles which further result in increased tone of the abdominal muscles and thereby mobilizing the fat leading to reduction in the fat. (2),(23) Thus, these exercises help in strengthening of the abdominal muscles. Mat exercises have proven their efficacy in abdominal muscle activation during these exercises. ${ }^{(14)}$ Studies have also shown that core strengthening exercises performed are not only significant for strengthening abdominal and lower back muscles, but also improve the endurance of abdominal muscles. ${ }^{(23)}$

The present study intended to assess the effect of core exercises on bilateral shoulder strength by assessing the strength of shoulder muscles and the results demonstrated that core strengthening improved overall shoulder strength significantly. (25) This increase in shoulder strength following core strengthening could be due to the link between core and upper extremity. The core is anatomically and physiologically connected to the shoulders as it has a major muscle link with the shoulder muscles which include Latissimus Dorsiand middle and lower fibres of Trapezius. These muscles also are part of minor core muscles. The core muscles can be major ones and minor muscles. The major core muscles included in core are Pelvic Floor Muscles, Transversus Abdominis, Multifidus, Internal and External Obliques, Rectus Abdominis, Erector Spinae (Sacrospinalis) especially the LongismusT horacis, and the Diaphragm and minor muscles like the Latissimus Dorsi, Gluteus Maximus, and Trapezius. ${ }^{(9)}$ This connection has been proved in the study where EMG analysis was done to monitor recruitment pattern of core muscles during resisted isometric exercises of shoulders. The study demonstrated that all the shoulder exercises which were done with resistance had positive activity of core muscles. ${ }^{(2),(14)}$ Hence, the shoulder exercises elicit great level of trunk muscle activation (14) which justifies the connection between the core and upper extremity particularly shoulder. Furthermore, previous studies reveal that core strength has a positive and good correlation with upper extremity functions in tennis players ${ }^{(3),(13)}$ golfers ${ }^{(12)}$ and cricketers ${ }^{(9)}$ in which parameters such as serve velocity, drive distance and bowling speed were assessed. In a study done by Chow, Shim and Lim (2003), the EMG activity of core muscles were assessed during all the phases of tennis serve. The authors concluded that the core muscles were active 
through all the phases of service. Therefore, the core strength and stability training protocol are important in the sports training and rehabilitation programs. ${ }^{(12),(15)}$ It is an agreeable fact that core stability is important for all types of activities ranging from running to throwing ${ }^{(8)}$ which prove that core is the centre of all functional movements of upper as well as lower extremities.

Yet another explanation as to how core strength training might have led to improvement in shoulder strengths is that the exercises that are included in the protocol do not only include a single body segment but it involves the body as a whole. For example the exercises like push ups, arm circles, the saw, spine stretch forward etc. incorporatethe activation of upper body segments. $^{(3)}$

The present study had a few limitations. Firstly, there was no control group. The presence of control group (non-obese subjects) would have given a better picture about the effectiveness. Secondly, due to time constraint, shoulder strength alone was considered for assessment with no consideration of assessment of endurance, hand strength and upper extremity function. Hence, future studies should incorporate the assessment of shoulder endurance, hand strength assessment along with functional assessment of upper extremity. Lastly, EMG analysis to study individual shoulder muscle recruitment was not performed due to unavailability of equipment.

\section{CONCLUSION AND CLINICAL IMPLICA- TION}

From the present study we can conclude that five week core strengthening protocol has a significant impact on the shoulder strength, irrespective of dominant or non-dominant side. The result of the present study, also gives a clue about the relation between core and shoulder. Therefore, as a part of rehabilitation program, core strengthening has to be included in patients with shoulder injuries.

Conflict of Interest: None declared.

Source of funding: None.

\section{REFERENCE}

1. Cavuoto L Nussbaum M. The influences of obesity and age on functional performance during intermittent upper extremity tasks. Journal of Occupational and Environmental Hygiene. 2014; 11(9):583-590.

2. Welling A, Nitsure P. Comparative study between mat, swiss ball and theraband exercises on abdominal girth. Int $\mathbf{J}$ Physiother Res. 2015; 3(4):1142-49.

3. Heathe Monger, Blain Harisso. The acute effect of Pilates exercise on lower extremity maximal strength. International Journal of Exercise Science. 2006; 9(3): 283-290.

4. Keevil V, Luben R, Dalzell N, Hayat S, Sayer A, Wareham N et al. Cross-sectional associations between different measures of obesity and muscle strength in men and women in a British cohort study. J Nutr Health Aging. 2015; 19(1):3-11.

5. Rodbard HW, Fox KM, Grandy S. Impact of obesity on work productivity and role disability in individuals with and at risk for diabetes mellitus. American Journal of Health Promotion. 2009 May; 23(5):35360.

6. Tomlinson DJ, Erskine RM, Morse CI, Winwood K, Onambélé-Pearson G. The impact of obesity on skeletal muscle strength and structure through adolescence to old age. Biogerontology. 2016 Jun 1;17(3):467-83.

7. Akuthota V, Nadler SF. Core strengthening. Arch Phys Med Rehabil 2004; 85 (3 Suppl 1):S86-92.

8. Sung D, Park S, Kim S, Kwon M, Lim Y. Effects of core and non-dominant arm strength training on drive distance in elite golfers. Journal of Sport and Health Science. 2016; 5(2):219-225.

9. Kim J, Lee DY, Yu J, Kim J, Hong J. The influence of abdominal muscles on shoulder isometric muscular strength. 
Indian Journal of Science and Technology. 2015; 8(25).

10. Leetun DT, Ireland ML, Willson JD, Ballantyne BT, Davis IM. Core stability measures as risk factors for lower extremity injury in athletes. Medicine \& science in sports \& exercise. 2004 ; 36(6):926-34.

11. Simoneau JA, Colberg SR, Thaete FL, Kelley DE. Skeletal muscle glycolytic and oxidative enzyme capacities are determinants of insulin sensitivity and muscle composition in obese women. The FASEB Journal. 1995; 9(2):273-8.

12. Kevin Hilligan B. The Relationship between core stability and bowling speed in asymptomatic male indoor action cricket bowlers. [Master's Degree in Technology]. Durban University of Technology.

13. Chow JW, Shim JH, Lim YT. Lower trunk muscle activity during tennis serve. Journal of science and medicine I Sport. 2003 Dec 1;6(4):512-8.

14. Mayo MJ, Grantham JR, Balasekaran GO. Exercise-induced weight loss preferentially reduces abdominal fat. Medicine and Science in Sports and Exercise. 2003; 35(2):207-13.

15. Core stabilitytesting and strengthening [Internet]. 1st Ed.Steps Physo 2015. Available from: Core $\% 20$ Stability $\% 2$ 0testing\%20and\%20strengthening $\% 20$ Handouts\%20\%202015\%20(2).pdf [Date of Access: 19 October2016]

16. Mohan V, Pradeepa R, Anjana R, Joshi S, Bhansali A, Deepa M et al. Prevalence of generalized \& abdominal obesity in urban $\&$ rural India - the ICMR-INDIAB Study (Phase-I) [ICMR - INDIAB-3]. Indian J Med Res. 2015; 142(2):139.

17. Mårin P, Oden B, Björntorp P. Assimilation and mobilization of triglycerides in subcutaneous abdominal and femoral adipose tissue in vivo in men: effects of androgens. The Journal of Clinical Endocrinology \& Metabolism. 1995; 80(1):239-43.

18. Kibler WB, Press J, Sciascia A. The role of core stability in athletic function. Sports Medicine. 2006; 36(3):189-98.

19. Bohannon RW. Reference values for extremity muscle strength obtained by hand-held dynamometry from adults aged 20 to 79 years. Archives of physical medicine and rehabilitation. 1997 Jan 31;78(1):26-32.

20. WHO expert consultation. Appropriate body-mass index for Asian populations and its implications for policy and intervention strategies. The Lancet 2004;363:157-63.

21. Stenholm S, harris TB, Rantanen T, Visser M, Kritchevsky SB, Ferruccci L. Sarcopenic obesity - definition, etiology and consequences. Curr Opin Clin Nutr Metab Care. 2008 November ; 11(6): 693700.

22. Pi-Sunyer FX. Obesity: criteria and classification. Proceedings of the Nutrition Society. 2000 Nov 1;59(04):505-9.

23. Obesity and overweight. World Health Organiztion. 2013; 1-4. Available from http://www.who.int/ mediaceFntre/factsheets.

24. McCarthy HD, Ellis SM, Cole TJ. Central overweight and obesity in British youth aged 11-16 years: cross sectional surveys of waist circumference. Bmj. 2003 Mar 22;326(7390):624.

25. Wagner JS. Convergent validity between field tests of isometric core strength, functional core strength, and sport performance variables in female soccer players.Diss. Boise State University, 2010. 